\title{
O ser-com-o-outro na condição sorodiscordante: uma abordagem fenomenológica da vulnerabilidade individual ao HIV
}

\author{
Fernanda da Mata Vasconcelos Silva ${ }^{1}$, \\ Sandro Márcio Moura de Senna², \\ Francisca Márcia Pereira Linhares ${ }^{3}$, \\ Fatima Maria da Silva Abrão ${ }^{4}$, \\ Tatiane Gomes Guedes 5
}

\section{RESUMO}

Compreender a sorodiscordância e a vulnerabilidade individual ao HIV nas relações de ser-com-o-outro sorodiscordante. Estudo qualitativo, ancorado na Fenomenologia Hermenêutica de Martin Heidegger. Participaram do estudo oito pacientes soropositivos e suas parcerias sorodiscordantes, totalizando 16 participantes. A entrevista foi o instrumento utilizado para obtenção das narrativas vividas pelos casais. Os conceitos fenomenológicos de "ser-com" e "ser-no-mundo", descritos por Heidegger, permitiu que os sentidos e significados relacionados ao fenômeno da sorodiscordância fossem evidenciados de forma detalhada. As construções sociais de masculinidade, a reduzida capacidade do casal em negociar prática de sexo seguro, o uso da terapia antiretroviral como fator de proteção ao HIV acrescidos das influências culturais foram evidenciados como as principais situações de vulnerabilidade individual da existência sorodiscordante. A compreensão do significado existencial de ser-casal-sorodiscordante, segundo a estrutura ontológica "ser-um-com-o-outro" instiga mudanças da práxis do enfermeiro, oportunizando um atendimento diferenciado e integral ao casal sorodiscordante.

Descritores: Sorodiagnóstico da AIDS; Comportamento Sexual; Parceiros Sexuais; Vulnerabilidade em Saúde; Hermenêutica.

\footnotetext{
${ }^{1}$ Enfermeira, Mestre em Enfermagem. Docente da Pós-Graduação Lato sensu do Instituto Nacional de Ensino, Sociedade e Pesquisa. Recife, PE, Brasil. E-mail: nandadamata34@gmail.com.

${ }^{2}$ Filósofo, Doutor em Filosofia. Professor Adjunto do Departamento de Filosofia da Universidade Federal de Pernambuco. Recife, PE, Brasil. E-mail: sandrosenna@gmail.com.

${ }^{3}$ Enfermeira, Doutora em Nutrição. Professora Adjunta do Departamento de Enfermagem da Universidade Federal de Pernambuco. Recife, PE, Brasil. E-mail: marciapl27@gmail.com.

${ }^{4}$ Enfermeira, Doutora em Enfermagem. Professora Adjunta do Departamento de Enfermagem da Universidade de Pernambuco. Recife, PE, Brasil. Email: fatima.abrao@upe.br.

${ }^{5}$ Enfermeira, Doutora em Enfermagem. Professora Adjunta do Departamento de Enfermagem da Universidade Federal de Pernambuco. Recife, PE, Brasil. E-mail: tatigguedes@yahoo.com.br.
}

\section{Como citar esse artigo:}

Silva FMV, Senna SMM, Linhares FMP, Abrão FMS, Guedes TG. O ser-com-o-outro na condição sorodiscordante: uma abordagem fenomenológica da vulnerabilidade individual ao HIV. Rev. Eletr. Enf. [Internet]. 2018 [acesso em: ];20:v20a07. Disponível em: http://doi.org/10.5216/ree.v20.47256. 


\section{INTRODUÇÃO}

A Terapia Antirretroviral (TARV) resultou no aumento da expectativa de vida de pessoas que convivem com o Vírus da Imunodeficiência Humana (HIV) e na possibilidade de reconstrução de projetos pessoais, inclusive de relacionamentos afetivos com pessoas com sorologia negativa, chamados casais sorodiscordantes ${ }^{(1)}$.

Ser sorodiscordante significa uma possibilidade do ser humano existir como ser-no-mundo, enquanto parceiro afetivo-sexual de outro ser com sorologia distinta da sua. Para acompanhar as mudanças no perfil da epidemia, faz-se necessário uma releitura da assistência prestada para atender de forma integral às pessoas que vivem com HIV (PHVA) e suas parcerias afetivas ${ }^{(2-3)}$.

Os conhecimentos advindos da fenomenologia hermenêutica de Martin Heiddeger serviram, no presente estudo, de referencial teórico para a compreensão do significado existencial de ser um casal sorodiscordante, segundo a estrutura ontológica da relação de um ser com o outro no mundo. Na fenomenologia, a condição humana do "ser" tem sentido na temporalidade, ou seja, as experiências passadas agem, influenciam e condicionam as ações enquanto ser-com-o-outro no mundo(4). Os sentidos e significados atribuídos a fatos cotidianos predizem a maneira de agir de cada indivíduo e, por conseguinte, determinam quão vulnerável ele encontra-se para determinadas situações ${ }^{(5)}$. O termo vulnerável remete à suscetibilidade das pessoas a problemas e danos à saúde ${ }^{(6)}$. Para compreender os fatores de vulnerabilidade a que uma pessoa está exposta, é oportuno interpretar a forma pela qual ela se percebe no mundo.

Embora o impacto psicológico e social, vivenciado pelos pacientes que convivem com o HIV, seja documentado na literatura científica, o impacto da infecção e das questões advindas da sorodiscordância ainda é pouco discutido ${ }^{(3)}$. Neste sentido, objetivou-se compreender a sorodiscordância e a vulnerabilidade individual ao HIV nas relações de ser-com-o-outro sorodiscordante à luz da Fenomenologia Hermenêutica de Heidegger.

\section{MÉTODO}

Estudo com abordagem qualitativa, desenvolvido com base nos Consolidated Criteria for Reporting Qualitative Research ${ }^{(7)}$. O referencial Heideggeriano subsidiou a compreensão da constituição existencial dos indivíduos em seu contexto-vital e contribuiu para apreender a forma pela qual o ser-casal-sorodiscordante vive, sente e pensa sobre as questões de vulnerabilidade individual ao HIV no cotidiano.

Participaram oito usuários, cadastrados em um serviço de assistência especializada e as respectivas parcerias afetivas que mantinham uma relação de sorodiscordância ao HIV, que totalizaram 16 participantes. Foram incluídas pessoas maiores de 18 anos, PHVA e que mantinham relacionamento com parceria de sorologia discordante. Excluíram-se casais que não apresentaram o exame sorológico para HIV com data igual ou inferior a 12 meses da data marcada para entrevista.

As entrevistas individuais dos integrantes soropositivos ocorreram em um consultório reservado para tal fim. Já com os cônjuges soronegativos, as entrevistas foram realizadas em locais escolhidos por cada um.

A entrevista semiestruturada, eleita enquanto instrumento de coleta de dados para obtenção das narrativas vividas dos casais sorodiscordantes, permitiu que os sentidos e significados relacionados ao fenômeno de sorodiscordância fossem evidenciados de forma detalhada ${ }^{(8)}$. Ela teve início a partir de uma questão que guiou o processo de coleta: "o que significa para você estar em um relacionamento sorodiscordante?". 
As entrevistas foram gravadas e transcritas na íntegra, fator que favoreceu uma leitura detalhada das falas e, posteriormente, a descrição do fenômeno. Para facilitar a compreensão do leitor e garantir o anonimato, os participantes foram identificados conforme os exemplos a seguir: C1M+: Casal 1, Masculino, Soropositivo ao HIV; C1M-: Casal 1 Masculino, soronegativo ao HIV.

Utilizou-se os conceitos fenomenológicos de "ser-com" e "ser-no-mundo" para associar as narrativas de acordo com os núcleos de sentidos ${ }^{(9)}$. A partir das semelhanças e diferenças discursivas, criaram-se cinco grupos temáticos para interpretar fenomenológica e hermeneuticamente a sorodiscordância e o sentido de se colocar em uma situação de vulnerabilidade individual ao HIV.

A pesquisa foi aprovada pelo Comitê de Ética e Pesquisa da Universidade Federal de Pernambuco, (Parecer no 1.628.499) e delineada em conformidade às exigências da Resolução № 466/12.

\section{RESULTADOS E DISCUSSÃO}

Dos casais participantes, cinco informaram ser heterossexuais e três mantinham relações afetivas com parceiros homossexuais masculinos, totalizando 10 homens e seis mulheres, com idade variável entre 23 e 63 anos para o sexo masculino e 37 a 54 anos para o sexo feminino. Será apresentado cada casal para melhor compreender o fenômeno da sorodiscordância e abordar fenomenologicamente questões relacionadas à vulnerabilidade individual destes pares ao HIV.

\section{- Casal 1:}

○ C1M+: 23 anos, protestante, soropositivo há cinco meses. Convive em relação estável de namoro há quatro anos. Responsável financeiro da relação. Boa convivência com familiares, porém os mesmos não sabem de sua opção sexual e, apenas, as duas irmãs sabem da sorologia positiva ao HIV. Iniciou recentemente a TARV. Apresenta carga viral detectável.

○ C1M-: 38 anos, ateu, atualmente encontra-se desempregado. Boa relação com seus familiares, porém os mesmos não sabem do seu namoro, da sua opção sexual e da sorologia positiva do seu parceiro.

\section{- Casal 2:}

○ C2F+: 46 anos, católica, soropositiva há 16 anos, em relação estável com parceiro único há quatro anos. Responsável financeira pela família. Divorciada, no segundo relacionamento sorodiscordante, apresenta uma boa relação com os dois filhos e demais familiares. Todos sabem de sua sorologia. Faz uso da TARV há 16 anos e sua carga viral está indetectável.

- C2M-: 52 anos, católico, em relacionamento sorodiscordante há quatro anos, tendo conhecimento da sorologia da parceira antes do início da relação. Atualmente está desempregado. Mantém um bom relacionamento com seu único filho e familiares, porém estes não sabem da sorologia de sua parceira.

\section{- Casal 3:}

○ C3M+: 36 anos, católico, soropositivo há dois anos, mantém uma relação estável com parceiro único há um ano e cinco meses, sem filhos, desempregado. Boas relações familiares que aceitam 
a relação homossexual, porém não sabem de sua sorologia positiva. Em uso contínuo da TARV, encontra-se assintomático e com carga viral indetectável.

- C3M-: 30 anos, católico, responsável financeiro pela família, atua como agente de negócios, sem filhos. Tem um bom relacionamento com seus familiares, que não sabem da sorologia do seu parceiro, mas aceitam sua opção sexual.

\section{- Casal 4:}

- C4F+: 54 anos, católica, soropositiva há 14 anos, em um casamento sorodiscordante há 12 anos, porém apenas há quatro anos o parceiro tomou conhecimento de sua sorologia. Autônoma, é responsável, junto com o parceiro, pelas despesas familiares. Apresenta um bom relacionamento com seus quatro filhos e demais parentes, todavia, apenas um dos filhos não aceita sua sorologia positiva ao HIV. Faz uso contínuo da TARV e encontra-se com carga viral indetectável.

- C4M-: 63 anos, católico, passou oito anos convivendo matrimonialmente sem conhecimento da soropositividade ao HIV da parceira. Trabalha como autônomo. Bom relacionamento com seus filhos e familiares, porém os mesmos não sabem da sorologia da parceira.

\section{- Casal 5:}

- C5M+: 48 anos, católico, soropositivo há 18 anos, casado há 25 anos. Encontra-se aposentado por incapacidades decorrentes da aids, considera-se o responsável financeiro pela família. Boa relação com sua esposa, dois filhos e familiares, porém apenas a cônjuge sabe da sua sorologia. Faz uso contínuo da TARV e encontra-se com carga viral indetectável.

- C5F-: 51 anos, católica, tem conhecimento da soropositividade do parceiro desde o momento da descoberta, sete anos após o casamento. Desenvolve um trabalho autônomo para complementar a renda familiar. Bom relacionamento com seus dois filhos e familiares, que não sabem da sorologia do seu esposo.

\section{- Casal 6:}

- C6F+: 40 anos, sem religião, convive com o vírus do HIV há dois anos e em relacionamento estável de namoro há um ano e três meses. Desempregada, "do lar", recebe auxílio financeiro do fundo de amparo social concedido ao filho especial. Tem um bom relacionamento com a criança e demais familiares e todos sabem e aceitam sua sorologia. Apresenta-se assintomática, mas com carga viral detectável em decorrência da infecção por sífilis. Em uso contínuo da TARV e do tratamento para sífilis.

- C6M-: 42 anos, sem religião, tem conhecimento da positividade ao HIV da parceira antes do inicio da relação. Autônomo, sem filhos. Bom relacionamento com seus familiares que desconhecem a condição sorológica de sua parceira.

\section{- Casal 7:}

- C7M+: 40 anos, católico, casado há 13 anos e convive com o HIV há 20. Aposentado pelo INSS por incapacidades decorrentes da aids. Sem filhos, mantém um bom relacionamento com todos os familiares que conhecem e aceitam sua sorologia. Em uso contínuo da TARV. Apresenta carga viral indetectável. 
- C7F-: 37 anos, católica, atualmente trabalha como técnica de enfermagem. Considera-se responsável financeira da família, junto com o esposo. Casada há 13 anos, sem filhos, mantêm boas relações com seus familiares que sabem da situação de sorodiscordância vivenciada por eles.

\section{- Casal 8:}

- C8M+: 35 anos, católico, soropositivo há três anos e namora com parceira fixa há um ano. Aposentado pelo INSS por distúrbio mental, considera-se responsável financeiro da relação. Sem filhos, estabelece boas relações com seus familiares. Faz uso da TARV de forma irregular e sua carga viral encontra-se detectável.

- C8F-: 43 anos, católica, ciente da sorologia do parceiro desde o inicio da relação. Vendedora autônoma, sem filhos. Bom relacionamento com familiares que não sabem da soropositividade do parceiro.

A "heterossexualização" da Aids acentuou-se em decorrência do estilo de vida sexual adotado por muitas mulheres que se relacionam sexualmente, de forma exclusiva, com os maridos e acabam por dispensar meios de prevenção por considerá-los parceiros fixos e fiéis ${ }^{(10)}$. O aumento progressivo do número de mulheres infectadas, caracterizado por "feminização da Aids"(5), não é motivado apenas pelas condições econômicas e sociais, mas também pela dificuldade da mulher em negociar práticas seguras de sexo e por ela assumir, muitas vezes, uma posição submissa de gênero na sociedade ${ }^{(5,10)}$.

A instabilidade na situação laboral está presente na vida de 10 integrantes do estudo. Os padrões brasileiros de desigualdade a exemplo da baixa escolaridade, má remuneração, índices elevados de desemprego e moradias em comunidades carentes contribuem, de forma significativa, para o aumento da epidemia ${ }^{(10)}$.

O uso sistemático da TARV proporciona à PHVA uma terapêutica de alta eficácia, que estabiliza a patologia de forma a deixar indetectável a carga viral na corrente sanguínea ${ }^{(11)}$. No presente estudo, em apenas dois dos casos, a carga viral encontrava-se detectável. Estudos relatam que uma pessoa com HIV sem nenhuma outra Infecção Sexualmente Transmissível (IST) e que segue uma TARV com carga viral indetectável, apresenta eficácia no nível de prevenção do contágio similar a do preservativo quando usado de modo adequado(1,12). Tal informação corrobora com a ideia que relações estáveis tendem a "rotinização" da intimidade entre cônjuges sorodiscordantes e ocorre uma suspensão do sexo seguro(3).

Quanto ao tempo de relacionamento, houve uma variação de um ano e três meses a 25 anos. A estabilidade nos relacionamentos pode estar relacionada ao fato do casamento ser considerado uma instituição ancorada no ideal de amor romântico, no qual se tem o outro no papel de extensão de si(13).

A infecção pelo HIV aconteceu na vida de dois casais (C1 e C5) após a prática sexual fora do casamento. Estudos mostram que a maioria das transmissões do HIV ocorre em um contexto de relacionamentos estáveis ${ }^{(5,14)}$. O relacionamento dos casais $\mathrm{C} 2$ e $\mathrm{C} 6$ iniciaram com os parceiros negativos cientes da soropositividade de suas parceiras, fato que ratificou estudo que o parceiro soronegativo também teve acesso a maiores informações sobre a epidemia, eficácia da TARV e formas de transmissão da doença, engajando-se, conscientemente, em relacionamentos com pessoas sorologicamente positivas ao $\mathrm{HIV}^{(12)}$. 
Os casais referiram bom relacionamento familiar, porém, em quatro deles (C2, C4, C6, C8), a sorologia positiva é desconhecida pelos familiares da parceria soronegativa. No caso dos casais C1, C3 e C5, a sorodiscordância é desconhecida pelas famílias dos dois integrantes da relação. Da mesma forma, apenas no casal C1 a opção sexual e a diferença sorológica não são conhecidas pela família de ambos.

Por meio das narrativas dos participantes, é possível acessar este Ser e compreender as questões relativas à sorodiscordância e vulnerabilidade individual, vivenciadas por eles a partir deles mesmos. Entende-se, portanto, que há uma constante necessidade de desvelar o que se encontra encoberto para que seja possível enxergar melhor os aspectos intrínsecos aos indivíduos e as relações que eles estabelecem com outros seres e o mundo, por eles mesmos e perceber os fenômenos apreendidos tal qual se apresentam ${ }^{(9)}$.

Nessa perspectiva, construíram-se cinco grupos temáticos para analisar fenomenologicamente os discursos, a partir dos conceitos fenomenológicos de "ser-com" e "ser-no-mundo", propostos por Heidegger.

\section{O pior momento da minha vida}

A experiência da soropositividade ao HIV, por meio da confirmação diagnóstica da sorologia positiva, modifica o curso de vida e a representação individual sobre a doença ${ }^{(15)}$. Altera a relação dos sujeitos com o tempo, evidenciada pela preocupação explícita com a morte iminente, conforme descrito na narrativa:

[...] pra mim foi uma sentença de morte... receber essa notícia 20 anos atrás, que era quase um marco na situação[...] (C7M+)

Alguns participantes descreveram a forma conforme a notícia foi conferida da seguinte maneira: “o pior momento da minha vida":

[...] eu estava grávida de três meses quando descobri que estava com isso [...] pra mim foi um choque muito grande [...] foi o pior momento da minha vida [...] e o bebê eu perdi por conta dos medicamentos para o HIV (C6F+).

Compete ao enfermeiro, um dos profissionais responsáveis pelo aconselhamento pós-teste com resultado da sorologia no contexto da Atenção Básica, desenvolver habilidades para comunicar a notícia da soropositividade. Percebe-se, no entanto, um despreparo do enfermeiro e demais profissionais, atuante nesse nível de atenção à saúde, em acolher o paciente com a devida consideração aos aspectos culturais e emocionais envolvidos no referido processo ${ }^{(2,5,16)}$. As compreensões prévias sobre o vírus e a síndrome, absorvidas pelas pessoas durante a vivência diária no mundo condicionam, de modo impessoal, a forma de pensar sobre a própria saúde e possibilidades de tratamento. Uma abordagem integral e holística, a qual envolva o paciente e a parceria discordante, abre novas e motivadoras perspectivas para enfrentamento da patologia e adesão ao tratamento.

\section{Divergência de sentimentos para falar a verdade}

Revelar a sorologia para a família envolve medo de discriminação e julgamento social(10). O momento de revelação do diagnóstico é considerado um tema tenso e delicado para todos envolvidos com o HIV:

[...] contar a ele foi muito difícil... eu senti uma dificuldade imensa... porque eu tinha medo de perder e ao mesmo tempo tinha medo de esconder [...] (C2F+);

[...] minha dificuldade mesmo foi contar para minha familia porque até hoje meu pai e minha mãe não sabem (C1M+). 
A insegurança em revelar a soropositividade é maior entre os casais constituídos antes do diagnóstico(10). A insegurança e o medo do término da relação leva à omissão da sorologia positiva, às vezes durante anos:

[...] já vai fazer uns 10 anos que a gente se encontrou e ela não falou nada para mim. A amiga dela disse: tais com AIDS também, porque ela tem este problema há muitos anos e eu acho que você pegou também (C4M-).

Conhecer a sorologia do cônjuge implica em temores e dúvidas que interferem de forma direta no sercasal $^{(17)}$. O ser inserido, no mundo, na condição de parceiro sorodiscordante organiza questões conforme as próprias necessidades e em função das preocupações pessoais ${ }^{(13,17)}$. Neste caso, a prevenção ao HIV e a Aids deve ser vista enquanto prática que contemple as subjetividades do sujeito e o panorama de vida do mesmo.

O acolhimento do(a) integrante negativo pelos serviços de saúde é primordial, pois proporciona o esclarecimento de dúvidas, aconselhamento psicológico para minimizar a ansiedade e angústia relacionadas à nova realidade, orientações direcionadas para prevenção do vírus e acompanhamento clínico, o qual confere maior segurança e estabilidade na relação do casal, pois tal prática é determinante para fortalecer e auxiliar o soropositivo no enfrentamento da epidemia ${ }^{(2-18)}$. Nesse sentido, o enfermeiro na prática cotidiana de atendimento aos pacientes soropositivos, deve atentar-se para incluir suas parcerias no planejamento de suas ações.

\section{Experiência desesperadora}

A falta de "percepção do risco" em adquirir o HIV subsidiou a "surpresa" em receber a notícia da soropositividade do companheiro(a). Este momento foi descrito como "uma experiência desesperadora":

\section{[...] fiquei pasmo, fiquei assim perplexo, mas infelizmente tinha acontecido e não tinha mais como voltar no tempo[...] (C1M-).}

O temor é um modo existencial em que o ser-humano, enquanto ser-no-mundo, age quando se sente ameaçado $^{(18)}$. Tal medo permite ao ser-humano refletir sobre a situação, compreender a si dentro do contexto da sorodiscordância e agir de forma autêntica nas relações de preocupação com os outros ${ }^{(9,19)}$.

Para as parcerias soronegativas dos casais C2, C3 e C7, agrega-se à concepção de amor os sentimentos de cuidado, apoio, solidariedade e responsabilidade. O ser dos homens tem sentido na temporalidade, assim, as experiências passadas direcionam o estar no mundo e a relação com o outro(4); logo, as experiências relativas a cada um deles, no passado, refletem a forma que superam as dificuldades da vida. O suporte conjugal, familiar e social aparecem em estudos enquanto incentivadores da pessoa que convive com HIV para continuar o tratamento ou até mesmo, quando necessário, manter sigilo do diagnóstico ${ }^{(2,5,16)}$.

\section{Não é o fim do mundo}

"Não é o fim do mundo", foi uma expressão utilizada na fala de um dos participantes que possibilitou para esse grupo temático duas vertentes de análise: a prevenção ao HIV.

[...] a gente só faz de camisinha [...] às vezes ele bebe e quer fazer sem nada, mas eu falo que só pode ser com camisinha. (C8F-) e o não ter medo de infectar-se [...] não tenho medo porque estou com a pessoa que amo e quando a gente ama não deve ter obstáculo nenhum sobre isto [...] tem que encarar naturalmente [...] (C2M-); 
Ao considerar que a PHVA convive em uma relação de sorodiscordância, faz-se necessário pensar na manutenção do status negativo do cônjuge. Algumas situações são consideradas "não controláveis" pelas pessoas que vivenciam esta realidade $\mathrm{e}^{(13-14,20)}$.

[...] eu não funciono com preservativo [...] disse a ela que não tinha problema de eu pegar [...] (C2M-).

Apesar dos casais relatarem o uso contínuo do preservativo masculino nas relações sexuais, percebe-se que existem muitas barreiras culturais, educacionais e emocionais que interferem na manutenção desta técnica segura.

Destarte, evidencia-se que o relacionamento passa a ser relido pelo casal que juntos buscam superar os desafios envolvidos na sorodiscordância(10). É necessário, pois, uma visão ampliada do enfermeiro, de forma a propiciar um cuidado integral aos casais sorodiscordantes, que valorize os aspectos da vulnerabilidade individual e contribua com a qualidade de vida dessa população específica.

\section{Só acontece com os outros}

Passados 30 anos do início da epidemia, os conceitos de comportamentos e "grupos de risco" para o HIV, construídos socialmente, permanecem inseridos nos indivíduos de forma a perceberem-se invulneráveis ao $\mathrm{HIV}^{(15)}$. Fato demonstrado na fala do entrevistado $\mathrm{C} 5 \mathrm{M}+$, para o qual, a Aids "parecia distante" da realidade:

[...] você só pensa em usar preservativo quando você tem a situação [...] você só pensa que vai acontecer com os outros [...] (C5M+).

Nos relacionamentos estáveis e duradouros, pressupõe-se a negligência quanto ao uso sistemático do preservativo pelo casal ${ }^{(14,20)}$. Constatou-se que a reduzida capacidade feminina em negociar práticas de sexo seguro constitui outro fator de vulnerabilidade ao HIV na relação sorodiscordante:

[...] às vezes tento fazer com que ele use a camisinha, ele não aceita [...] sempre acha ruim [...] antes de contar para ele, eu tive relação sem camisinha [...] tive medo de perdê-lo (C2F+).

Estudos demonstram que as mulheres não exigem o uso do preservativo por temer introduzir desconfiança na relação e não querer desagradar seus parceiros afetivos ${ }^{(5,14,20)}$.

As construções sociais de masculinidade e dominação constituem fator de vulnerabilidade ao $\mathrm{HIV}^{(14)}$. É "natural" o homem "correr riscos" e ser aceito socialmente pela própria virilidade.

[...] eu nunca gostei de usar preservativo, tanto é que não usei e peguei ( $\mathrm{C} 5 \mathrm{M}+)$;

[...] a gente sempre usa camisinha [...] mas já aconteceu sem [...] não tenho medo de pegar [...] isso é fichinha diante do que já passei na vida (C6M-).

Cabe ao profissional de saúde explicar, durante a consulta, que a diminuição do risco de transmissão secundária ao tratamento antirretroviral com carga viral indetectável existe, porém não é nula.

\section{CONSIDERAÇÕES FINAIS}

A análise das narrativas dos participantes ancoradas nos conceitos existenciais de "ser-com" e "ser-nomundo", propostos pela fenomenologia Hermenêutica de Martin Heidegger, desvelou o fenômeno da 
sorodiscordância ao HIV, evidenciando desafios e barreiras para a manutenção da vida sexual segura. As construções sociais de masculinidade, a reduzida capacidade do casal em negociar prática de sexo seguro, a demora na revelação do diagnóstico para a parceria, o uso da TARV enquanto fator de proteção, acrescidos das influências culturais, foram evidenciados entre as principais situações de vulnerabilidade individual da existência sorodiscordante.

Cada ser é único, e o que caracteriza sua existência é a forma pela qual ele compreende-se enquanto Serno-mundo. Desvelar o sentido existencial do fenômeno da sorodiscordância contribuiu para o crescimento da enfermagem enquanto ciência do cuidar, instigando mudanças da sua práxis. Os dados, aqui apresentados, sugerem que o enfermeiro deve apreender a forma como as PHVA vivem, sentem e pensam sobre as questões de vulnerabilidade individual a partir do seu contexto vital. Evidencia ainda, a necessidade de serviços de saúde diferenciados para o atendimento integral do casal sorodiscordante, que compreende o portador e a sua parceria, tendo em vista o risco existente de transmissão do HIV.

Reconhecer situações de vulnerabilidade existente na relação de ser-com-o-outro, a partir deles mesmos, proporciona um cuidado de enfermagem direcionado às reais necessidades desse público, contribuindo com a adesão ao tratamento e a consciência da necessidade de estabelecer hábitos de vida saudáveis.

\section{REFERÊNCIAS}

1. Bazzi AR, Leech AA, Biancarelli DL, Sullivan M, Drainoni ML. Experiences Using Pre-Exposure Prophylaxis for Safer Conception Among HIV Serodiscordant Heterosexual Couples in the United States. AIDS Patient Care STDS [Internet]. 2017 [acesso em: 21 jun. 2018];31(8):348-55. Disponível em: http://doi.org/10.1089/apc.2017.0098.

2. Kempfer SS, Birolo IVB, Meirelles BHS, Erdmann AL. Reflexão sobre um modelo de sistema organizacional de cuidado de enfermagem centrado nas melhores práticas. Rev Gaucha Enferm [Internet]. 2010 [acesso em: 21 jun. 2018];31(3):562-6. Disponível em: http://dx.doi.org/10.1590/S1983-14472010000300022.

3. Maksud I. Silêncios e segredos: aspectos (não falados) da conjugalidade face à sorodiscordância para o HIV/AIDS. Cad Saude Publica [Internet]. 2012 [acesso em: 21 jun. 2018];28(6):1196-204. Disponível em: http://dx.doi.org/10.1590/S0102311X2012000600018.

4. Fernandes MA. Da temporalidade da existência e do instante: uma investigação ontológico-existencial segundo o pensamento de Heidegger. Nat. hum. [Internet]. 2015 [acesso em: 21 jun. 2018];17(1):32-57. Disponível em:

http://pepsic.bvsalud.org/scielo.php?script=sci_arttext\&pid=S1517-24302015000100003.

5. Nicolau SM, Schraiber LB, Ayres JRCM. Mulheres com deficiência e sua dupla vulnerabilidade: contribuições para a construção da integralidade em saúde. Cien Saude Colet [Internet]. 2013 [acesso em: 21 jun. 2018];18(3):863-72. Disponível em: http://dx.doi.org/10.1590/S1413-81232013000300032.

6. Ayres JRCM, Paiva V, França Junior I. From natural history of disease to vulnerability. New York: Routledge; 2011.

7. Tong A, Sainsbury P, Craig J. Consolidated criteria for reporting qualitative research (COREQ): a 32-item checklist for interviews and focus groups. Int J Qual Health Care [Internet]. 2007 [acesso em: 21 jun. 2018];19(6):349-57. Disponível em:

https://doi.org/10.1093/intqhc/mzm042.

8. Paula CC, Souza IEO, Cabral IE, Padoin SMM. Movimento analítico-hermenêutico heideggeriano: possibilidade metodológica para a pesquisa em enfermagem. Acta paul. enferm. [Internet]. 2012 [acesso em: 21 jun. 2018];25(6):984-9. Disponível em:

http://dx.doi.org/10.1590/S0103-21002012000600025.

9. Heidegger M. Ser e Tempo. Petrópolis: Editora Vozes; 2012. (Publicação original em 1927)

10. Silva AM, Camargo Junior KR. A invisibilidade da sorodiscordância na atenção às pessoas com HIV/AIDS. Cien Saude Colet [Internet]. 2011 [acesso em: 21 jun. 2018];16(12):4865-75. Disponível em: http://dx.doi.org/10.1590/S1413-81232011001300035. 11. Teixeira M, Mendes MT, Borba KP, Pereira EM, Borba E. Avaliação da qualidade de vida de mulheres vivendo com HIV. Rev Enferm UFSM [Internet]. 2015 [acesso em: 21 jun. 2018];5(2):360-7. Disponível em: http://dx.doi.org/10.5902/2179769215277. 12. Lorenzo-Redondo R, Fryer HR, Bedford T, Kim EY, Archer J, Pond SLK, et al. Persistent HIV-1 replication maintains the tissue reservoir during therapy. Nature [Internet]. 2016 [acesso em: 21 jun. 2018];530(7588):51-6. Disponível em:

http://doi.org/10.1038/nature16933. 
13. Reis RK, Gir E. Convivendo com a diferença: o impacto da sorodiscordância na vida afetivo-sexual de portadores do HIV/AIDS. Rev Esc Enferm USP [Internet]. 2010 [acesso em: 21 jun. 2018];44(3):759-65. Disponível em: http://dx.doi.org/10.1590/S0080$\underline{62342010000300030 .}$.

14. Arraes CO, Palos MAP, Barbosa MA, Teles SA, Souza MM, Matos MA. Masculinity, vulnerability and prevention of STD/HIV/AIDS among male adolescents: social representations in a land reform settlement. Rev Lat Am Enfermagem [Internet]. 2013 [acesso em: 21 jun. 2018];21(6):1266-73. Disponível em: http://dx.doi.org/10.1590/0104-1169.3059.2363.

15. Castrighini CC, Reis RK, Neves LAS, Brunini S, Canini SRMS, Gir E. Avaliação da autoestima em pessoas vivendo com HIV/AIDS no município de Ribeirão Preto-SP. Texto contexto - enferm. [Internet]. 2013 [acesso em: 21 jun. 2018];22(4):1049-55. Disponível em: http://dx.doi.org/10.1590/S0104-07072013000400022.

16. Said AP, Seidi EMF. Sorodiscordância e prevenção do HIV: percepções de pessoas em relacionamentos estáveis e não estáveis. Interface (Botucatu) [Internet]. 2015 [acesso em: 21 jun. 2018];19(54):467-78. Disponível em: http://dx.doi.org/10.1590/180757622014.0120.

17. Oliveira LEC. O ser-com como compartilhamento da verdade do ser-aí. Saberes [Internet]. 2010 [acesso em: 21 jun. 2018];3(esp.):57-70. Disponível em: https://periodicos.ufrn.br/saberes/article/view/877.

18. Salimena AMO, Oliveira MTL, Paiva ACPC, Melo MCSC. Mulheres portadoras de câncer de útero: percepção da assistência de enfermagem. Revista de Enfermagem do Centro Oeste Mineiro [Internet]. 2014 [acesso em: 21 jun. 2018];4(1):909-20. Disponível em: http://www.seer.ufsj.edu.br/index.php/recom/article/view/401.

19. Cerezer C, Flores APM, Zanardi I. Introdução aos estudos Heideggerianos a partir de Ser e Tempo: uma renovação contemporânea da íntima questão do Ser. Thaumazein [Internet]. 2012 [acesso em: 21 jun. 2018];5(9):67-79. Disponível em: https://www. periodicos.unifra.br/index.php/thaumazein/article/view/87.

20. Marques Junior JS, Gomes R, Nascimento EF. Masculinidade hegemônica, vulnerabilidade e prevenção ao HIV/AIDS. Cien Saude Colet [Internet]. 2012 [acesso em: 21 jun. 2018];17(2):511-20. Disponível em: http://dx.doi.org/10.1590/S1413-

81232012000200024. 